\title{
Conflicts between Local and Global Spatial Frameworks Dissociate Neural Representations of the Lateral and Medial Entorhinal Cortex
}

\author{
Joshua P. Neunuebel, ${ }^{1,3}$ D. Yoganarasimha, ${ }^{3}$ Geeta Rao, ${ }^{1,3}$ and James J. Knierim ${ }^{1,2,3}$ \\ ${ }^{1}$ Krieger Mind/Brain Institute, Johns Hopkins University, Baltimore, Maryland 21218, ${ }^{2}$ Solomon H. Snyder Department of Neuroscience, Johns Hopkins \\ University School of Medicine, Baltimore, Maryland 21205, and ${ }^{3}$ Department of Neurobiology and Anatomy, University of Texas Medical School at \\ Houston, Houston, Texas 77030
}

\begin{abstract}
Manipulation of spatial reference frames is a common experimental tool to investigate the nature of hippocampal information coding and to investigate high-order processes, such as cognitive coordination. However, it is unknown how the hippocampus afferents represent the local and global reference frames of an environment. To address these issues, single units were recorded in freely moving rats with multi-tetrode arrays targeting the superficial layers of the lateral entorhinal cortex (LEC) and medial entorhinal cortex (MEC), the two primary cortical inputs to the hippocampus. Rats ran clockwise laps around a circular track partitioned into quadrants covered by different textures (the local reference frame). The track was centered in a circular environment with distinct landmarks on the walls (the global reference frame). Here we demonstrate a novel dissociation between MEC and LEC in that the global frame controlled the MEC representation and the local frame controlled the LEC representation when the reference frames were rotated in equal, but opposite, directions. Consideration of the functional anatomy of the hippocampal circuit and popular models of attractor dynamics in CA3 suggests a mechanistic explanation of previous data showing a dissociation between the CA3 and CA1 regions in their responses to this localglobal conflict. Furthermore, these results are consistent with a model of the LEC providing the hippocampus with the external sensory content of an experience and the MEC providing the spatial context, which combine to form conjunctive codes in the hippocampus that form the basis of episodic memory.
\end{abstract}

\section{Introduction}

The entorhinal cortex and hippocampus are crucial for forming episodic memories in humans and episodic-like memories in animals (Scoville and Milner, 1957; O'Keefe and Nadel, 1978; Squire, 1987; Cohen and Eichenbaum, 1993). The medial entorhinal cortex (MEC) and lateral entorhinal cortex (LEC) provide the primary cortical input to the hippocampus. MEC cells fire in patterns of repeating, triangular grids that tile the environment (Hafting et al., 2005), show head-direction tuning, or fire along environmental boundaries (Sargolini et al., 2006; Savelli et al., 2008; Solstad et al., 2008). In contrast, LEC cells show little spatial tuning in an empty, open field (Hargreaves et al., 2005; Yoga-

\footnotetext{
Received March 3, 2013; revised April 5, 2013; accepted April 13, 2013.

Author contributions: J.J.K. designed research; D.Y. and G.R. performed research; J.P.N., D.Y., G.R., and J.J.K. analyzed data; J.P.N. and J.J.K. wrote the paper.

This work was supported by National Institutes of Health Grants R01 NS39456 and T32 NS07467. We thank M. R. Neunuebel, M. Hussein Schuler, and M. Yassa for comments on a previous version of this manuscript and F. Savelli and S. S. Deshmukh for helpful discussions.

The authors declare no competing financial interests.

Correspondence should be addressed to James J. Knierim, Johns Hopkins University, Krieger Mind/Brain Institute, 338 Krieger Hall, 3400 North Charles Street, Baltimore, MD 21218. E-mail: jknierim@jhu.edu.

J.P. Neunuebel's present address: Janelia Farm Research Campus, Howard Hughes Medical Institute, 19700 Helix Drive, Ashburn, VA 20147

D. Yoganarasimha's present address: National Brain Research Centre, NH-8, Manesar, Gurgaon, Haryana 122051, India.

DOI:10.1523/JNEUROSCI.0946-13.2013

Copyright $\odot 2013$ the authors $\quad 0270-6474 / 13 / 339246-13 \$ 15.00 / 0$
}

narasimha et al., 2011), but the tuning becomes strongly enhanced in the presence of discrete objects, showing spatial firing fields and "memory" for locations previously occupied by objects (Deshmukh and Knierim, 2011). Correspondingly, animals with lesions to the MEC and LEC show deficits in spatial and objectplace/object-context processing, respectively (Van Cauter et al., 2013; Wilson et al., 2013). In support of episodic memory, the hippocampal formation may combine external sensory input from the LEC with a self-motion-based spatial framework from the MEC to generate context-specific memories of items in place or events in context (although a partial integration of these streams may occur before the hippocampus; Furtak et al., 2012) (Fig. 1A).

Principal neurons in the hippocampus preferentially fire when an animal moves through specific locations (O'Keefe, 1976). Early experiments suggested that the location-specific firing of these place cells was controlled by distal landmarks (O'Keefe and Conway, 1978). However, local surface cues and boundaries exert a powerful influence on place cells and spatial behavior (Shapiro et al., 1997; Zinyuk et al., 2000; Brown and Skaggs, 2002; Knierim, 2002; Renaudineau et al., 2007). When an apparatus is translated relative to a global framework, the local frame of reference dominates over the global framework in the control of place cells and behavior (Knierim and Rao, 2003; Hamilton et al., 2008; Siegel et al., 2008). When the global and local cues are rotated relative to each other, the local cues can 


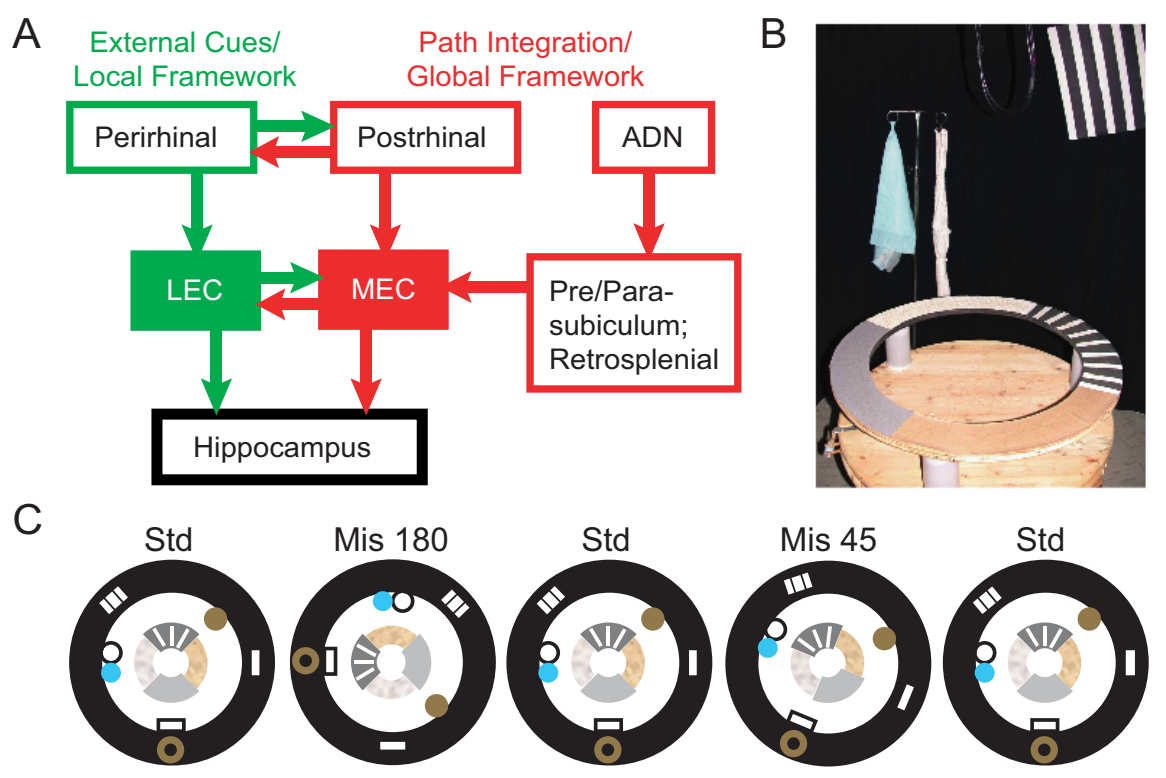

Figure 1. Experimental design. $A$, Simplified schematic illustrating the information flow through the hippocampal formation. The MEC, in conjunction with postrhinal cortex, retrosplenial cortex, anterior dorsal nucleus of the thalamus (ADN), and the presubiculum and parasubiculum, may carry a path integration signal to the hippocampus, oriented by the global cues in the environment. The LEC, in conjunction with the perirhinal cortex, may convey local, external sensory input to the hippocampus. $\boldsymbol{B}$, Recording environment. $\boldsymbol{C}$, One day of the experimental protocol consisted of three standard sessions interleaved with two cue-mismatch sessions. The mismatch angles depicted are $180^{\circ}$ and $45^{\circ}$.

dominate if they are salient enough (Shapiro et al., 1997; Brown and Skaggs, 2002; Knierim, 2002; Renaudineau et al., 2007). Thus, the common dogma that place cells and hippocampusdependent spatial learning are primarily dependent on global/distal landmarks is no longer tenable (Knierim and Hamilton, 2011).

It is unknown whether information about local and global cues is transmitted to the hippocampus via different pathways. In the "double-rotation" protocol (Shapiro et al., 1997; Knierim, 2002), salient local and global cues are rotated in opposite directions. Using this protocol, Knierim (2002) showed that the global and local reference frames could simultaneously control CA1 place fields. Zinyuk et al. (2000) have shown similar simultaneous representations of local and global reference frames in rotating arenas. In the present experiment, we tested the hypothesis that information about the global framework was transmitted to the hippocampus by the MEC and information about the local framework was transmitted by the LEC.

\section{Materials and Methods}

Subjects and surgery. Seven male, Long-Evans rats (5-6 months old, 500-750 g; Charles River Laboratories) were housed individually, exposed to a $12 \mathrm{~h}$ light/dark circadian cycle (lights off at 12:00 P.M.), and had ad libitum access to water and food. When rats had been habituated for $\sim 14 \mathrm{~d}$, a custom-built recording drive that contained 20 independently moveable tetrodes (18 tetrodes and two references) was surgically implanted over the right hemisphere. In four rats, the drives were implanted vertically to target the MEC, with the most posterior electrode of the circular array $(\sim 1.5 \mathrm{~mm}$ diameter $)$ positioned $600-800 \mu \mathrm{m}$ anterior to the transverse sinus and $4.8-5.0 \mathrm{~mm}$ lateral to the midline. In three rats, the drives were implanted at a $25^{\circ}$ lateral angle to target LEC, with the middle of the circular array at coordinates $3.2-4.6 \mathrm{~mm}$ lateral and 7.2-7.7 mm posterior to bregma. All surgeries were performed under aseptic conditions, in compliance with National Institutes of Health guidelines and approved by the Institutional Animal Care and Use Committee at the University of Texas Health Science Center at Houston.

Training and recording. Rats recovered from the surgical procedure for 5-7 d, and then their body weights were reduced to $80-90 \%$ of their free-feeding weight. After a daily session of advancing tetrodes, rats were trained in a cuecontrolled environment to run laps clockwise (CW) around a circular track (outside and inside diameters of the track were 76 and $56 \mathrm{~cm}$, respectively). The track, which was centered in a black-curtained enclosure with six salient cues located at the periphery, was divided into four $90^{\circ}$ segments that were textured with different materials (Fig. 1B). A white-noise generator was centered under the table to help mask external auditory cues. During the initial training sessions, chocolate sprinkles were dispersed around the track, and the rats were trained to continuously navigate $\mathrm{CW}$ for the reward. A cardboard panel was placed in front of the rat if it attempted to move counterclockwise (CCW) until it reversed directions and continued circumnavigating CW. As behavior progressively improved, the reward was eventually reduced to one to two random locations on the track per lap. Training continued in this environment until units were detected and experiments were initiated. For MEC and LEC rats, training lasted on average 12 and $11 \mathrm{~d}$, respectively.

On experimental days, a baseline session, lasting 20-30 min, was recorded before the start of the experiment. The baseline session consisted of periods when the rat slept or was resting quietly in its holding dish. During behavioral sessions, rats ran five track sessions (Fig. 1C). Track sessions consisted of three standard sessions (STD; local and global cue relationship remained constant) interleaved with two mismatch sessions (MIS; local and global cues were rotated by equal amounts but in opposite directions, producing mismatch angles of $45^{\circ}, 90^{\circ}, 135^{\circ}$, or $\left.180^{\circ}\right)$. For example, a $180^{\circ}$ mismatch represents a $90^{\circ} \mathrm{CCW}$ local cue rotation plus a $90^{\circ} \mathrm{CW}$ global cue rotation. Mismatch angles were chosen in pseudorandom order. All experiments concluded with a 20-30 min baseline session to assess the stability of the recordings compared with the preexperiment baseline session.

Electrophysiological recordings. A Cheetah Data Acquisition System (Neuralynx) concurrently obtained up to 72 channels (18 tetrodes) of single-unit data and 21 channels of local field potential (LFP) activity. Neural signals were detected simultaneously on four fine microwire electrodes ( $12 \mu \mathrm{m}$ gold-plated nichrome) that were wound together to form a tetrode. The signals were amplified 2000-10,000 times and filtered between 0.6 and $6 \mathrm{kHz}$ (for units) or between 1 and $475 \mathrm{~Hz}$ (for LFP). The spike waveforms were sampled for $1 \mathrm{~ms}$ at $32 \mathrm{kHz}$, whereas LFPs were continuously sampled at $1 \mathrm{kHz}$. The rat's position was tracked with an overhead camera recording a circular array of light-emitting diodes (red and blue) positioned over the head of the rat and a $13 \mathrm{~cm}$ extension behind the head with additional diodes (green) at $30 \mathrm{~Hz}$.

For all tetrodes targeting the entorhinal cortex, each tetrode position was estimated from the total distance it was advanced after entering the brain. Additional insight was provided by the number of times each tetrode passed through regions with multiple units and regions that were relatively quiet (signaling transitions between gray and white matter), as well as the changing patterns in LFP activity. The presence of theta rhythm in the LFP and units with grid-cell activity (on some tetrodes) indicated that tetrodes were in the MEC area. After each day of recording, tetrodes were advanced $\sim 120 \mu \mathrm{m}$ to sample different cells across the multiple days of recording. Smaller movements were not considered sufficient to ensure new samples of independent cells. Experiments concluded after all tetrodes stopped detecting cells, which indicated that tetrodes were in layer I. For MEC, theta phase reversal also indicated that tetrodes were in or near layer I (Alonso and García-Austt, 1987a,b). For MEC, experiments concluded after 2-10 d. For LEC, experiments con- 
cluded after 10-22 d. Final recording site localization was determined using histological analysis (see below).

Unit isolation. Multiple waveform characteristics (i.e., spike amplitude peak, area under the waveform, and valley depth) recorded simultaneously on the four wires of a tetrode were used to isolate single units offline with a custom, interactive software program (WinClust, a Windowsbased program modeled on the XClust software originally designed by M. Wilson, Massachusetts Institute of Technology, Cambridge, MA). The isolation quality of a cell was rated on a subjective scale from 1 (very good) to 5 (poor) depending on the distance each cluster was separated from other clusters and from background noise. Cluster isolation was judged before examining any of the behavioral firing correlates of the cells. All cells rated as fair or better (categories 1-3) were potentially included in all analyses (for specific inclusion criteria, see below, Data analyses).

Data analyses. All analyses were performed on data that excluded offtrack firing by filtering the data to include only spikes occurring within the boundaries of the track. To remove behavioral periods when the rat was immobile, all samples in which the rat's velocity was $<1 \mathrm{~cm} / \mathrm{s}$ were also excluded. Circular, two-dimensional (2D) data were linearized by transforming the 2D locations of the rat into units of degrees on the track, and the mean firing rate of every cell was calculated for every one degree of the track. The linearized firing rate maps were smoothed using a Gaussian smoothing algorithm $\left(\sigma=5.34^{\circ}\right)$. After removing off-track firing and velocity filtering the data, cells that fired 20 spikes or more in at least one track session and had a mean firing rate $<10 \mathrm{~Hz}$ were considered active excitatory cells and were included in the quantitative analyses.

For any cells that met the inclusion criteria in the standard and mismatch sessions (excluding the cells with firing that appeared or disappeared in the mismatch session), the direction and angular distance that the rate map rotated was determined. The linearized rate map in the standard session was correlated with the linearized rate map for the mismatch session. The mismatch session rate map was then rotated in increments of $5^{\circ}$ and correlated with the standard session rate map at each rotation increment. The rotation producing the highest Pearson's product-moment correlation indicated the amount that the firing location was rotated.

The cellular response was categorized for all cells that met criteria in either the preceding standard or mismatch sessions. The responses of individual cells were separated into five types. The categories "appear" and "disappear" were based on the number of spikes a cell fired in the standard and mismatch sessions. If a cell fired $\geq 20$ spikes in the standard session but not in the mismatch session, it was classified as disappear. If it fired $\geq 20$ spikes in the mismatch session but not in the standard session, it was classified as appear. For the remainder, cells with high maximum correlations $(r \geq 0.6)$ at locations corresponding to a clockwise or counterclockwise rotation were classified as CW or CCW, respectively. If the maximum correlation between the standard and mismatch session was below 0.6, cells were considered ambiguous.

Population correlation matrices of spatial activity were created by constructing population firing rate vectors at each of the 360 locations on the track for any cell meeting criteria in either of the two sessions being correlated (Fig. 2A). The firing rate vectors for each bin of the standard session were correlated with the firing rate vectors for each bin of either the mismatch session or the subsequent standard session using a Pearson's product-moment correlation. This produced a $360 \times 360$ correlation coefficient matrix that was partitioned into regions associated with CW (global cue) or CCW (local cue) rotations (Fig. 2F). A band of high correlation located in either region shows that the population of cells rotated their firing location coherently in the corresponding direction. To quantify the location of each band, the mean correlation was calculated for each diagonal of the correlation matrix and represented as polar plots (Fig. 2F). For every region and mismatch angle, the peak mean correlation and the corresponding angle were determined for all STD versus STD and STD versus MIS matrices. To measure the directional strength of the correlation polar plots, the mean vector was calculated by summing the vectors corresponding to the distance and direction from the origin to each of the $3601^{\circ}$ bins of the polar plot and dividing the length of the summed vector by 360 .
To show that the locations of the peak correlations did not occur by chance at the angles corresponding to the local or global cue rotations, four different shuffling procedures were used, in which the columns, rows, bins, or positions of the mismatch session population correlation matrices were randomly shuffled (Fig. 2B-E) (Louie and Wilson, 2001). For the row shuffle, the 360 positional firing rate vectors of the mismatch session matrices were randomized. For the column shuffle, the cell identities were arbitrarily shuffled. For the bin shuffle, all of the position bins for each of the cells were randomized. For the positional circle shuffle, each rate map was circularly shifted $\mathrm{CW}$ by a random amount (minimum of $5^{\circ}$ ) for every cell. After each transformation, population firing rate vectors were created from the randomized data and correlated to the population firing rate vectors from the preceding standard session. The average correlation along each diagonal of the matrix was calculated to create 1D correlation graphs as described above. From these 1D graphs, the mean correlation was calculated for the bins that corresponded to the rotation angle ( \pm 10 bins) for each of the global and local sets of cues. The shuffling procedure was repeated 1000 times for each shuffle type. The location of the peak of the actual data was considered significant at a conservative $\alpha=0.01$ if $<10$ of the mean correlations from the 1000 repetitions of the shuffled data were greater than the score from the actual (unshuffled) data.

Statistical analyses were run in Excel (Microsoft), MATLAB (MathWorks), or Statistica (StatSoft). Circular statistics were calculated using functions from the MATLAB circular statistics toolbox. All statistical tests were two tailed with an $\alpha$ level of 0.05 , unless otherwise stated.

Histological procedures. Marker lesions were performed on a subset of tetrodes ( $10 \mu \mathrm{A}$ of positive current for $10 \mathrm{~s}$ ) after the completion of these experiments. Lesions were used to help identify tracks during histological reconstruction. The following day, rats were killed with an overdose of pentobarbital sodium/phenytoin sodium (Euthasol) and then perfused through the heart with formalin. Brains were sliced $(40 \mu \mathrm{m})$ in the coronal (LEC rats) or sagittal (for MEC rats) planes with a freezing microtome, mounted on microscope slides, and stained with cresyl violet. Images of sections were captured with a Moticam 2000 camera (Motic Instruments) that was attached to a Motic SMZ-168 stereoscope and saved as high-resolution JPEG files on a Dell computer. Electrode tracks and the tetrode that generated them were identified and assigned to a brain region based on the final location of the tetrode tip. To determine the anatomical layer for MEC and LEC, the distance traveled before the final placement of the tetrodes was calculated, assuming 15\% shrinkage from histological processing.

\section{Results}

To test whether the MEC and LEC segregate information about the local and global reference frames, we recorded single-unit activity from seven rats with multi-tetrode arrays targeting the superficial layers (the hippocampal input layers) of the MEC (four rats) and the LEC (three rats) (Fig. $3 A, B$ ). Rats circumnavigated CW a track with prominent local cues, located in the center of a black-curtained, circular environment containing six global cues (standard session) (Knierim, 2002). Neural recording sessions consisted of three standard sessions interleaved with two mismatch sessions. Mismatch sessions involved rotating the global cues CW and the local cues CCW by the same amount, for net cue mismatches of $45^{\circ}, 90^{\circ}, 135^{\circ}$, and $180^{\circ}$. Analyses were restricted to active, putative excitatory cells, which were defined as cells with a mean firing rate $<10 \mathrm{~Hz}$ and that fired at least 20 spikes during at least one session (Fig. $3 C, D$ ). The mean firing rate never exceeded $5 \mathrm{~Hz}$ for any of the cells in LEC, whereas the mean firing rate of $13 \mathrm{MEC}$ cells exceeded $10 \mathrm{~Hz}$, a pattern that replicates the findings of Deshmukh and Knierim (2011). During the first standard session of the day, 77\% of LEC (44 of 57) and $80 \%$ of MEC (77 of 96 ) units met inclusion criteria. A previous report (Yoganarasimha et al., 2011) on a subset of these data (i.e., the data from the first standard session of the day) showed that the LEC representations were spatially nonspecific, whereas the 
A

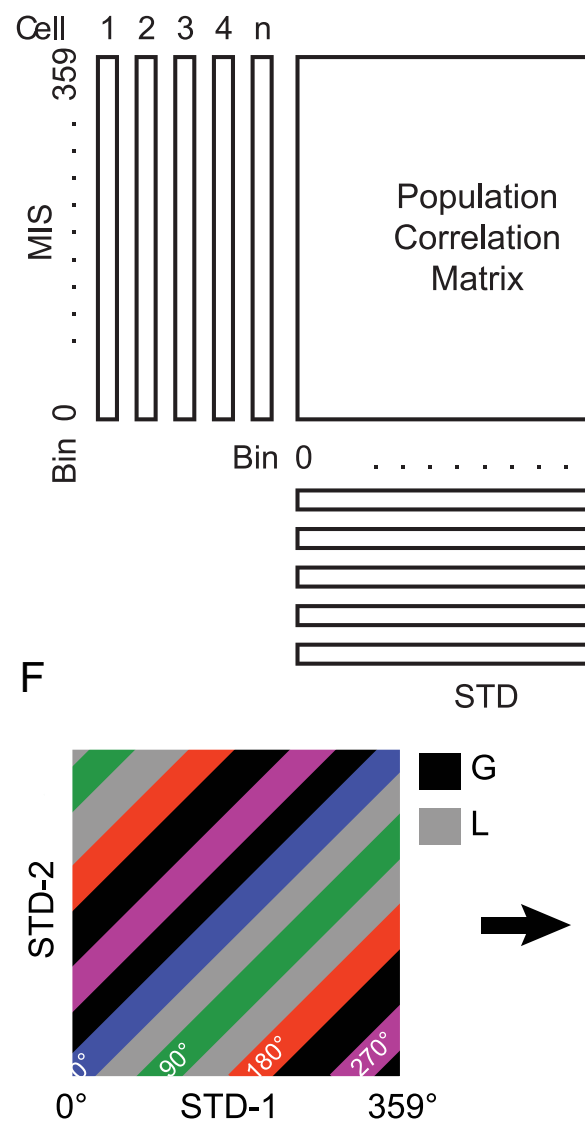

Shuffle Variations

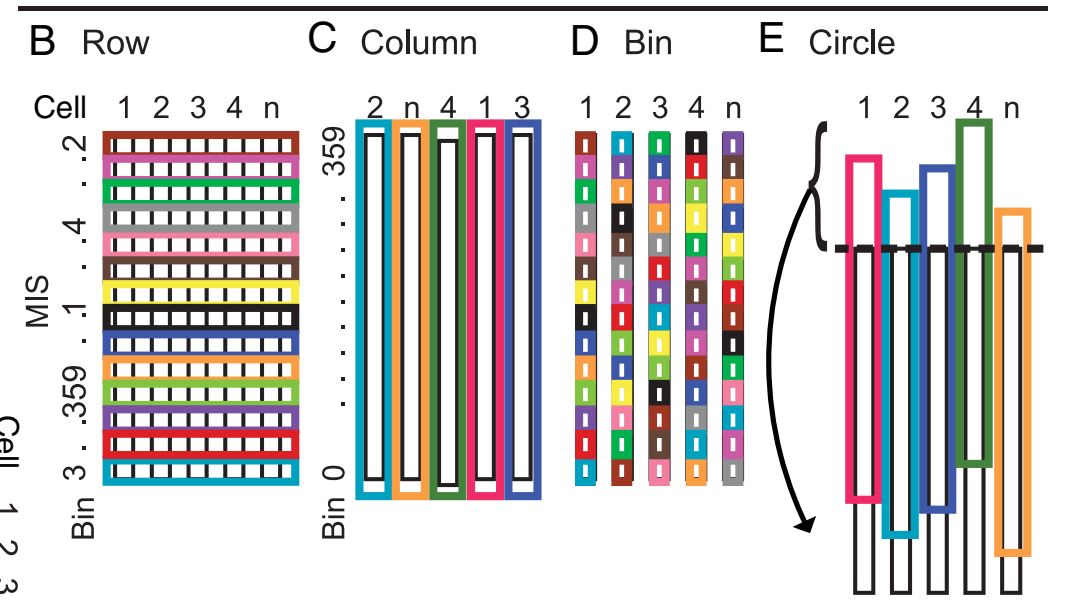

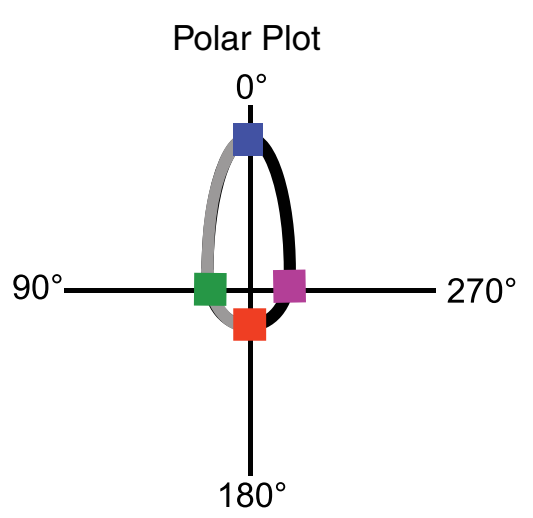

Figure 2. Data shuffling and reduction procedures for statistical analysis of correlation matrices. $A$, Illustration showing population correlation analysis for standard versus mismatch sessions. $B-E$, To determine whether the peak magnitudes of the correlation matrices were greater than expected by chance, four different shuffling procedures were used on the mismatch data to create null correlation matrices (Louie and Wilson, 2001). Shuffling the rows (B) kept each population vector intact but randomly redistributed the vectors to different locations on the track. Shuffling the columns $(\boldsymbol{C})$ kept the firing profile of each cell intact but randomly reassigned cell identifications. Randomly rearranging each bin in the mismatch data (D) completely randomized the dataset. Circularly shifting the firing rate map of each cell (E) kept the firing profile and identification of each cell intact but shifted the rate map along the track by a random amount, thus creating new activity vectors at each bin. $\boldsymbol{F}$, Illustration showing regions of the population correlation matrices used to calculate the mean correlations for the 360 diagonals. Blue, green, red, and violet lines show regions of the matrix used to determine mean correlations for diagonals $0^{\circ}, 90^{\circ}, 180^{\circ}$, and $270^{\circ}$, respectively. The shaded gray areas in the correlation matrix (diagonals $1^{\circ}-179^{\circ}$ ) represent a local cue response (L) (CCW rotation), whereas the black areas (diagonals $\left.181^{\circ}-359^{\circ}\right)$ indicate a global cue response $(\mathrm{G})(\mathrm{CW}$ rotation). Averaging the correlation values of the $2 \mathrm{D}$ matrix along the diagonals creates the $1 \mathrm{D}$ correlation curve in the middle. The curve presented here illustrates an idealized example (for a region with strong spatial firing) of a correlation curve between two standard sessions, in which the highest correlation is along the $0^{\circ}$ diagonal (demonstrating spatial stability between sessions) and the correlations decrease gracefully along adjacent diagonals. In STD-MIS comparisons, peaks occurring along the gray portion of the curve would indicate local cue control of the representation, whereas peaks occurring along the black portion of the curve would indicate global cue control. Transforming the Cartesian coordinates of the $1 \mathrm{D}$ correlation curve to a polar coordinate system created the polar plot shown at the right.

MEC representations showed significantly more spatial modulation (Fig. $3 E, F$; Mann-Whitney $U$ test, rank sum $=1450, p<$ $\left.10^{10}\right)$. The recording sites spanned the lateral-medial axis of the LEC and the posterodorsal-anteroventral axis of the MEC, corresponding to the projection zones to the dorsal-ventral hippocampus in both regions (for histology pictures, see Yoganarasimha et al., 2011, their Fig. 2).

To compare the responses of the entorhinal input directly to a previously published report of CA1 and CA3, we used the same types of analyses as the previous paper (Lee et al., 2004). Thus, although the LEC does not show strong spatial tuning and the MEC cells often had multiple firing fields on the track, the spikes from these cells were still the primary cortical drive underlying the spatial responses of individual place fields in the downstream dentate gyrus, CA3, and CA1 regions. Could the patterns of local-global control of the place cells be revealed in similar controls over the location-based rate maps of the less-specific input patterns of the entorhinal cortex? The first analysis classified indi- vidual cells according to their responses to the double-rotation manipulation. These classifications create some arbitrary distinctions between cells but are useful to compare with previous results from CA1 and CA3 (Lee et al., 2004) and to give an appreciation of how individual cells respond to the manipulations. Later analyses based on population data will provide added support for the conclusions reported in this initial analysis.

Examples of MEC cell responses to the double rotation are shown in Figure 4. Cell 1 had a firing field near the 5 o'clock position on the track in the standard sessions (STD 1 and STD 2). In the $45^{\circ}$ cue-mismatch session, the firing field rotated slightly $\mathrm{CW}$, which indicated global cue control. A rotation correlation analysis quantified the cue control (line graph to the right of the rate maps). The mismatch rate map was correlated with the STD 1 rate map at each of 72 rotational increments (each rotation was $5^{\circ}$; see Materials and Methods). For cell 1, the graph shows that the maximum correlation occurred when the rate map was rotated $25^{\circ} \mathrm{CW}$. We used a peak correlation magnitude criterion of 

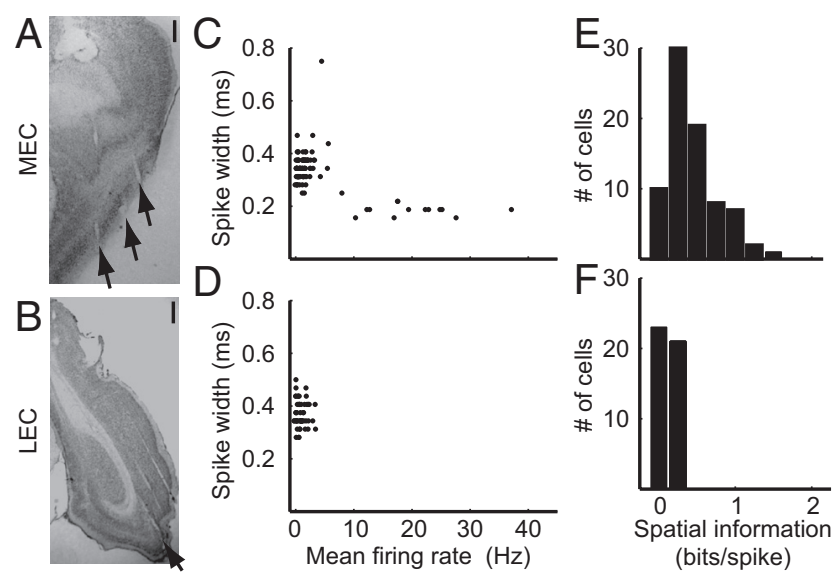

Figure 3. Characterization of entorhinal cell types. $A, B$, Histology examples show the locations of tetrodes targeting MEC $(\boldsymbol{A})$ and LEC $(\boldsymbol{B})$. Scale bars, $500 \mu \mathrm{m}$. Arrows indicate tips of tetrode tracks. Recordings from MEC and LEC were located in regions that project to both septal and temporal levels of the hippocampus. C, D, For all well-isolated MEC (C) and LEC (D) cells recorded in the first standard session of the day, the mean firing rates (hertz; abscissa) and spike widths (milliseconds; ordinate) were plotted to classify different cell types. Two distinct groups of cells were observed in the MEC (putative principal cells with wider spikes and a mean firing rate $<10 \mathrm{~Hz}$ and putative interneurons with narrower spikes and a mean firing rate $\geq 10 \mathrm{~Hz}$ ), whereas only one group of cells was recorded in the LEC (firing rate $<5 \mathrm{~Hz}$ ). $\boldsymbol{E}, \boldsymbol{F}$, Histograms show the spatial information scores based on $2 D$ rate maps for the first daily standard sessions of MEC $(\boldsymbol{E})$ and LEC $(\boldsymbol{F})$ cells. These data are nearly identical to those in the study by Yoganarasimha et al. (2011), with slight changes in the cell count attributable to differences in analysis inclusion criteria between the two studies.

0.6 (green line) to indicate that the rate maps were strongly correlated. This criterion was chosen as the value that best matched experienced observers' evaluations of whether two MEC or LEC rate maps appeared similar to each other. Cells 1-5 all had peak correlations $\geq 0.6$ at rotation angles that indicated $\mathrm{CW}$ rotation of the fields. Note that some cells had multiple fields (cells 2-4), indicating that they were likely to be grid cells. Although the correlation analyses produced multiple peaks for these cells, a single peak crossed the 0.6 correlation threshold, and thus the fields were considered to have rotated CW on average. Some cells (cells 6 and 7) had peak correlations that indicated CCW rotation. Many MEC cells (e.g., cells 8-12) had peak correlations $<0.6$, and the cue control was thus considered ambiguous. The ambiguity often resulted from a change in the number of firing fields on the track between the standard and mismatch sessions (e.g., cells 9-11). The final response types consisted of cells that met activity criteria for only one of the two sessions. For example, cells 13 and 14 fired only a few spikes in the standard session but developed strong firing fields in the mismatch session. Other cells (data not shown) had firing fields in the standard session but were silent in the mismatch session. For all such appear and disappear cells, inspection of the tetrode cluster patterns in the baseline sessions before and after the behavioral sessions showed that the cells were present in both baseline sessions, indicating that the appearance/disappearance of the fields was not an artifact of recording instability.

Examples of LEC responses to the double rotation are shown in Figure 5. Although most LEC cells showed poor spatial tuning, a few cells showed spatial biases that were consistent across the standard sessions. For example, cell 1 showed a disjointed spatial pattern of firing that was similar across all standard sessions (the STD 1 and STD 2 sessions of cell 1a and the STD 2 session of cell $1 \mathrm{~b}$; asterisks indicate that the STD 1 session of cell $1 \mathrm{~b}$ is the same as the STD 2 session of cell 1a). The correlation analyses indicated that, for both mismatch sessions, the rate maps had high correlations $\geq 0.6$ at an angle that indicated CCW control by the local cues. However, the large majority $(>85 \%)$ of LEC cells showed poor correlations at all angles, indicating an ambiguous response (cells 2-6). This ambiguity was not always attributable to the complete absence of spatial tuning. Cells 4 and 5 are examples of cells with consistent spatial biases in the standard sessions, but no rotation angle produced a high correlation, indicating that the mismatch sessions never matched the standard sessions.

Figure 6 shows the distribution of the different response types for the MEC and LEC. The distribution of cell types was significantly different between the areas $\left(\chi^{2}=31.8 ; p<0.001\right)$. In both areas, the most common response was ambiguous, accounting for $\sim 80 \%$ of the LEC cells and $\sim 50 \%$ of the MEC cells. Only a small number of cells were categorized as appear or disappear, showing that both MEC and LEC cells tended to be active in both sessions. Of most relevance to the present study, the cortical areas showed an opposite trend as to whether the global or local cues dominated the responses of the subset of cells that could be categorized as CW or CCW. In the LEC, eight cells were categorized as CCW (local cue control) and only one cell was categorized as CW (global cue control); this proportion was significantly different from the null hypothesis that the number of CW and CCW cells was equal (binomial test, $p=0.018$ ). In contrast, in the MEC, 14 cells were categorized as CCW and 46 as CW (binomial test, $p=0.000015)$. The difference between the MEC and LEC in the numbers of CW versus CCW cells was highly significant $\left(\chi^{2}=\right.$ $15.49 ; p<0.001$ ). Thus, although the number of cells that could be categorized as having rotated their spatial firing patterns either CW or CCW was a minority in both areas, the local cues dominated over the global cues in the LEC sample, whereas the global cues dominated over the local cues in the MEC sample.

The preceding analysis provided useful information about how individual cells respond to the double-rotation manipulation. However, the cell classification scheme leads to some unavoidably arbitrary assignments because of the need to set strict criteria regarding minimum correlation values and minimum number of spikes. As in our previous study of CA1 and CA3 (Lee et al., 2004), we supplemented these analyses with an approach that does not require classification of continuously varying response profiles into predefined categories. To measure the population responses to the cue manipulations, spatial correlation matrices were created from population firing rate vectors at each location on the track (Fig. $2 A$ ). The mean firing rate of every cell in the sample (normalized to its peak rate) was calculated for each $1^{\circ}$ bin of the circular track to create 360 firing rate vectors. The firing rate vectors of a standard session (STD 1) were correlated with the firing rate vectors from either the immediately succeeding mismatch session or the following standard session (STD 2). The STD 1 versus STD 2 correlation matrices for MEC produced a band of high correlation on the diagonal (Fig. 7A), showing that most MEC cells fired at a similar location in both standard sessions, which is consistent with the robust spatial representations in this region (Hafting et al., 2005). In the STD versus MIS correlation matrices, a band of high correlation was maintained for the $45^{\circ}, 90^{\circ}$, and $135^{\circ}$ mismatches, but the band was primarily degraded in the $180^{\circ}$ mismatch. Importantly, the band of correlation shifted upward with each mismatch amount (above the $45^{\circ}$ diagonal, represented by the dashed red line), indicating that the global reference frame controlled the MEC representations (Fig. $2 F)$. The correlation structure of the MEC matrix became increasingly degraded as the mismatch angle increased. In contrast to MEC, every LEC correlation matrix appeared un- 


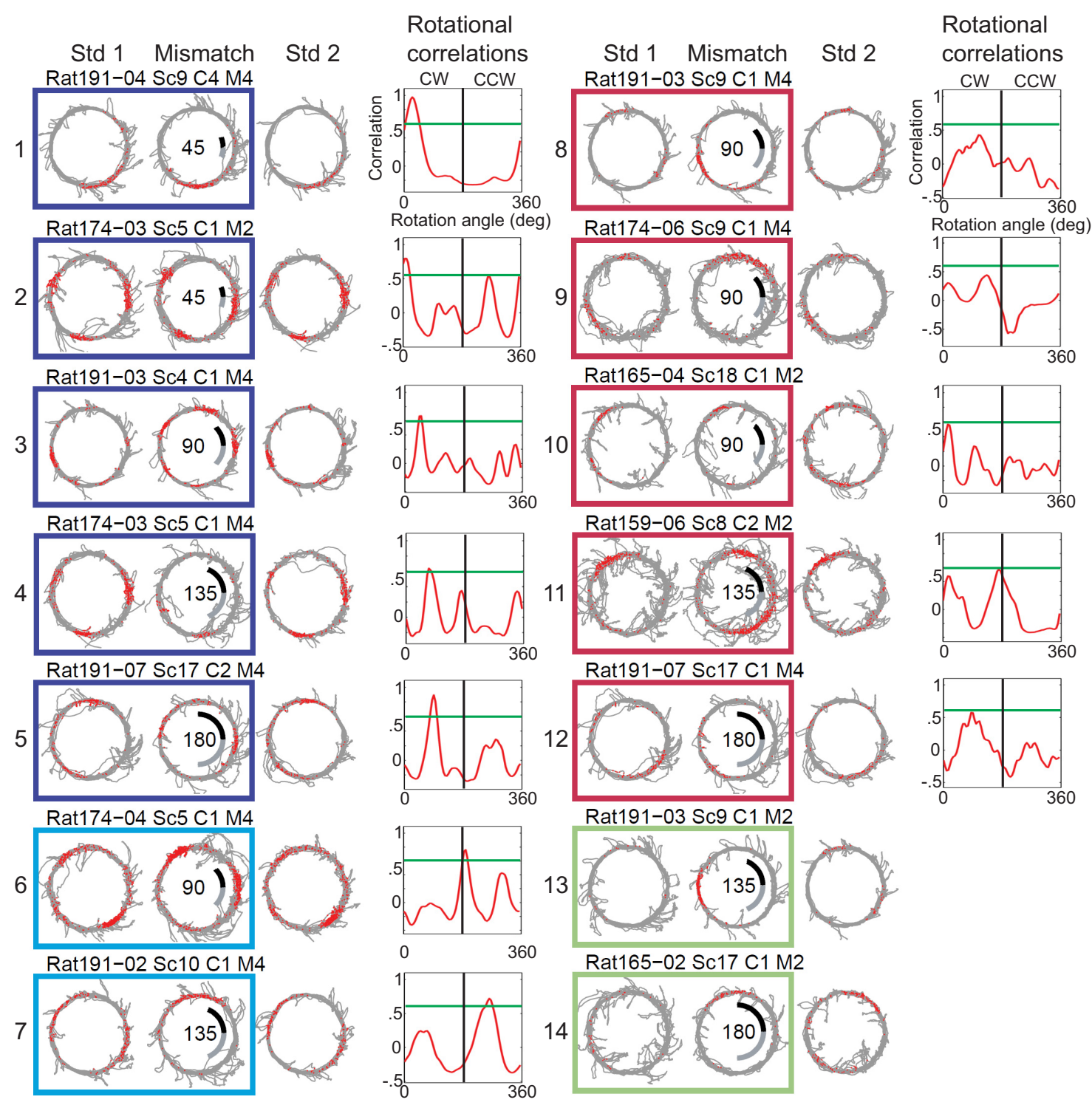

Figure 4. Examples of MEC cellular responses. Example spike (red points) and trajectory (gray line) plots of representative cells showing three consecutive sessions (standard, mismatch, and standard). Numbers in the center of all mismatch sessions indicate the total mismatch angle. The gray and black arcs show the amount of the local and global cue rotations, respectively. The colored boxes indicate the classification of the cell for the STD 1-MIS comparison: navy blue, CW rotation; cyan, CCW rotation; maroon, ambiguous response; and green, appearance of place field. To the right of each set of place fields is a graph of the rotation correlation analysis between the STD 1 and MIS sessions. Correlations above 0.6 (green line) were considered strong enough to indicate an unambiguous response to the mismatch. Peaks above 0.6 to the left or right of $180^{\circ}$ (black vertical line) indicated that the fields rotated CW or CCW, respectively, in the mismatch session. For a description of individual cells, see Results.

structured (Fig. 7B), suggesting that the spatially nonspecific LEC representations (Hargreaves et al., 2005; Yoganarasimha et al., 2011) showed considerable variability from one session to the next, even in the STD 1 versus STD 2 comparisons (but see next paragraph).

For quantitative analysis, the $2 \mathrm{D}$ correlation matrices were reduced to $1 \mathrm{D}$ polar plots by calculating the mean correlation of pixels in each of the 360 diagonals in the correlation matrices (Fig. $2 F$ ). Figure $8 A$ shows that the peak correlation for all MEC STD 1 versus STD 2 correlation matrices (gray lines) occurred near $0^{\circ}$, indicating the stability of the representations. For the mismatch sessions (red lines), the peak correlation shifted CW as the mismatch angle increased, corresponding to the amount of the global cue rotation, which confirmed the global cue control evident in the 2D matrices. For LEC, although most individual cells showed poor spatial tuning and the $2 \mathrm{D}$ correlation matrix did not show obvious structure, a small, local-cue-related signal was revealed in the polar plots (Fig. 8B). The peak correlations for the STD-STD plots (gray lines) were near 0 , and for every mismatch angle, the amount that the peak (green lines) shifted was within $9^{\circ}$ of the local cue rotation (although the LEC $135^{\circ}$ graph had a second peak that under-rotated the local cues). For both MEC and LEC populations, the highest correlations corresponded to the rotation $\left( \pm 9^{\circ}\right)$ of one of the cue sets $\left(\operatorname{LEC} 45^{\circ}=\right.$ 26; $\operatorname{LEC} 90^{\circ}=44 ; \operatorname{LEC} 135^{\circ}=76 ; \operatorname{LEC} 180^{\circ}=90 ; \operatorname{MEC} 45^{\circ}=$ 342 ; $\operatorname{MEC} 90^{\circ}=317$; $\operatorname{MEC} 135^{\circ}=290$; MEC $\left.180^{\circ}=274\right)$. The chance of the polar plot's peak occurring within $18^{\circ}$ of $180^{\circ}$ is 0.1 ; therefore, the likelihood of all eight polar plots occurring within $18^{\circ}$ of the corresponding cue rotation by chance is $0.1^{8}=10^{-8}$.

Although the polar plots showed a dissociation between the MEC and LEC based on the control of global and local reference frames, respectively, this effect might occur by chance if there was 


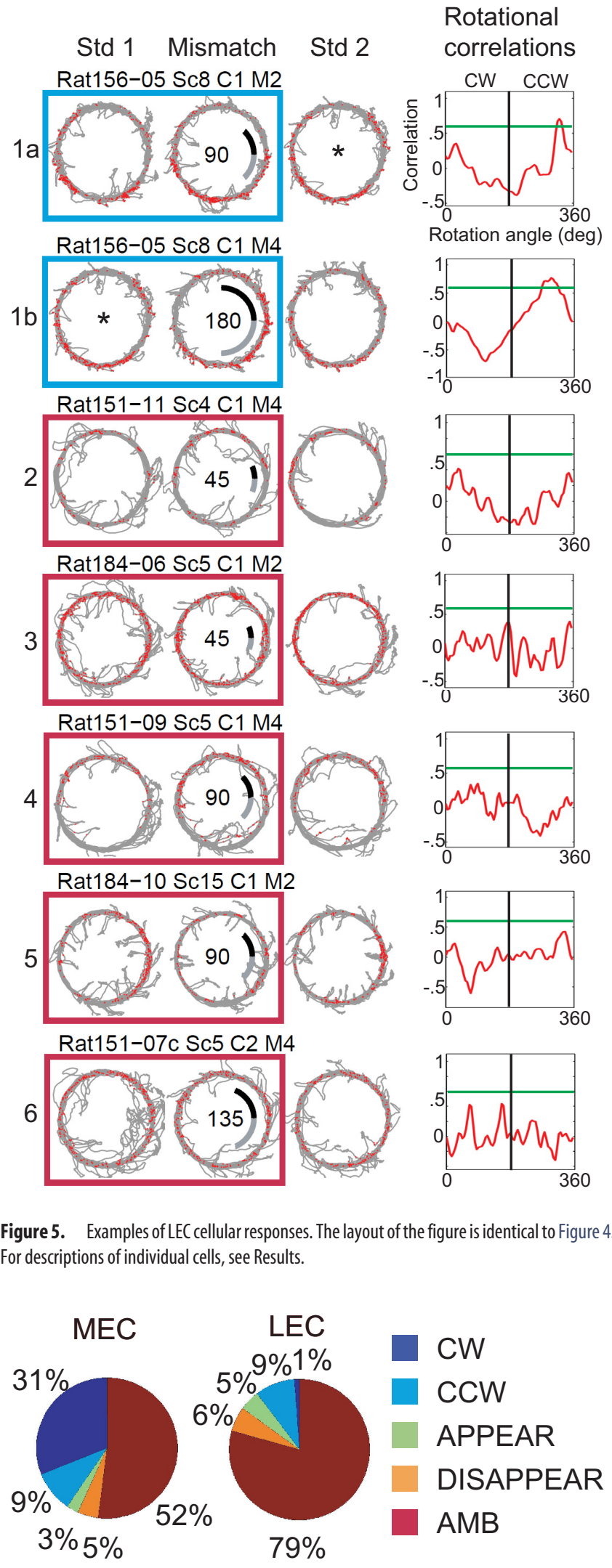

Figure 6. Proportion of cellular responses. Percentage of cells categorized as (W (navy blue), CCW (cyan), appear (green), disappear (orange), or ambiguous (AMB; maroon) for each region. The numbers of cells in each category are as follows: LEC: total (87), CW (1), CCW (8), appear (4), disappear (5), ambiguous (69); MEC: total (148), CW (46), CCW (14), appear(4), disappear (7), ambiguous (77). The cellular responses were significantly different between regions $\left(\chi^{2}=\right.$ $31.8 ; p<0.001)$.

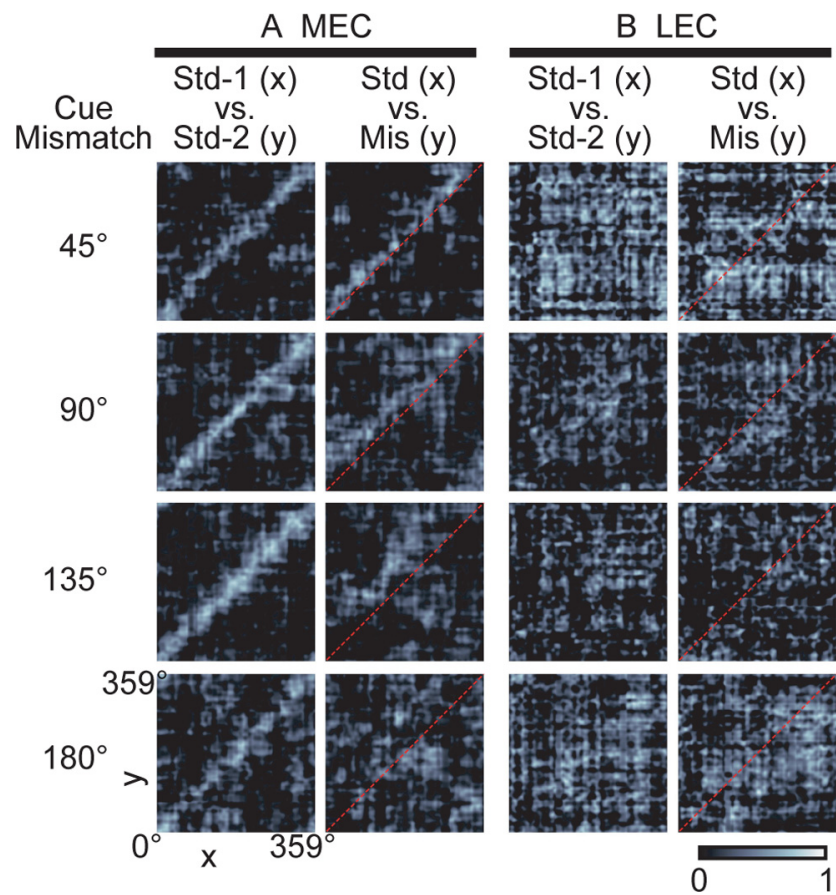

Figure 7. Population responses to cue-mismatch manipulations. Spatial correlation matrices were produced by correlating the normalized firing rate vectors for a standard session with those of the following mismatch or standard session. $A$, MEC representations maintained coherence in all standard-standard and standard-mismatch sessions, indicated by the bands of high correlation (white), which shifted above the main diagonal (dashed red line) in the mismatch session. The correlation degraded with the increasing magnitude of the local-global cue mismatch. $\boldsymbol{B}$, In contrast to the MEC, the LEC representations showed less obvious structure in either the standard-standard or standard-mismatch comparisons.

some consistent bias in the correlation matrices. To control for this possibility, four different shuffling procedures were used to randomize the structure of the mismatch session matrix of each region (see Materials and Methods). After shuffling the rows, columns, bins, or positions of the mismatch session matrices (Fig. 2B-E), the mean correlation for each diagonal of the 2D correlation matrix was calculated as before. The mean correlations from the bins corresponding to the local and global cue rotation ( \pm 10 bins) were averaged and compared with the unshuffled data. Figure $9 A$ shows the distributions of the 1000 iterations of the circle-shuffled data (Fig. $2 G$ ) across all mismatch angles. For each mismatch angle, the correlation value of the unshuffled MEC data (Fig. 9A, red line) affiliated with the global cues was above the shuffled distributions $(p<0.001)$. In contrast, the correlation value of the unshuffled MEC data corresponding to the local cues was never significantly larger than the shuffled distribution $(p>0.52)$ for all mismatch angles. The correlation value of the LEC peaks associated with the local cues was always significantly larger than the shuffled distributions for all mismatch angles (Fig. 9B) $(p<0.001)$. In contrast, the correlation value of the LEC peaks associated with the global cues was not significantly greater than the shuffled distributions $(p>$ $0.01)$. Similar results were obtained for all four types of shuffle analyses (Fig. 9B). In some cases of the small mismatch angles $\left(45^{\circ}\right.$ and $\left.90^{\circ}\right)$, the LEC global-cue-related correlation was significant $(p<0.01)$ for the shuffled distribution, because the LEC cells fired over large fractions of the track. However, in each case, the local-cue related correlation value was still larger than the global-cue-related value. 
A

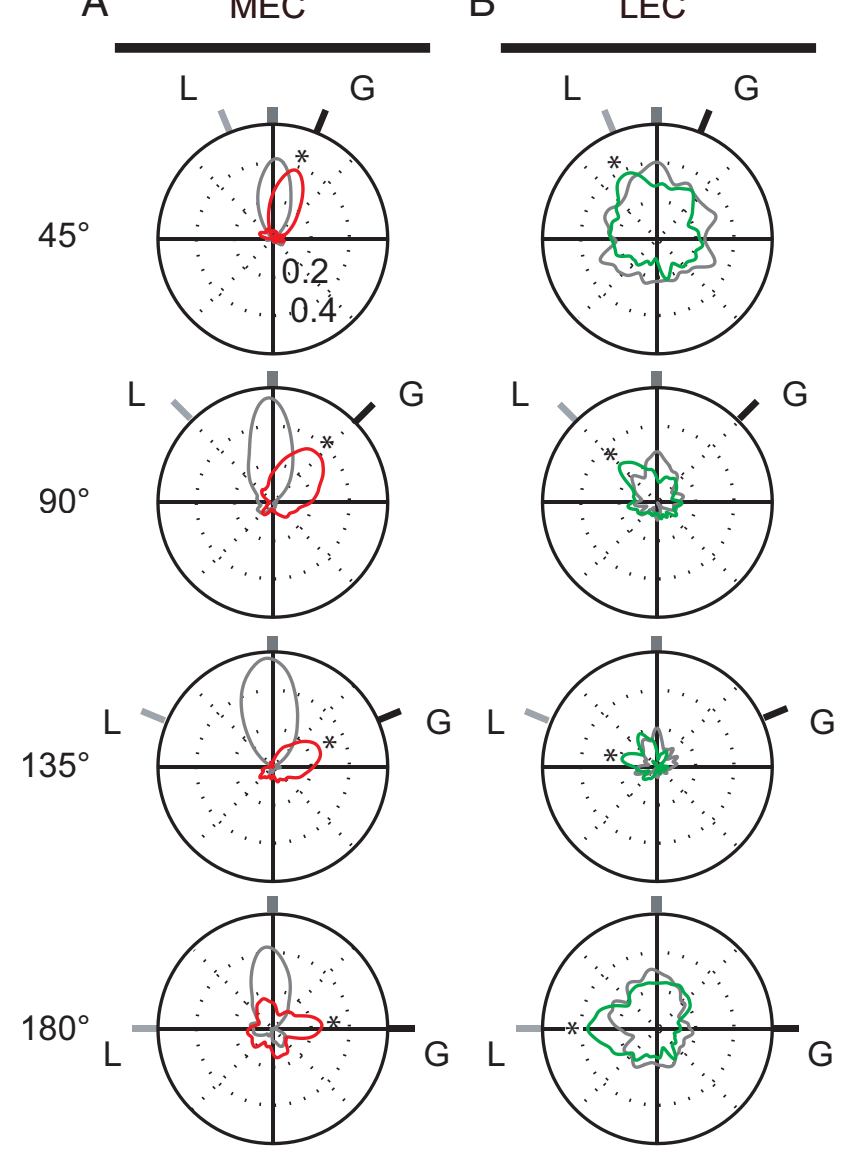

Figure 8. Polar plots demonstrate global cue control over MEC firing and local cue control over LEC firing. The polar plots were created from the LEC and MEC spatial correlation matrices to represent the population activity between STD 1 versus STD 2 (gray) and standard versus mismatch (color) sessions. The peaks (marked by asterisks) in the MEC plots (red) follow the global $(G)$ cues $(\boldsymbol{A})$, whereas the peaks in the LEC plots (green) follow the local $(\mathrm{L})$ cues $(\boldsymbol{B})$.

The global cue control seen in the MEC and local cue control observed in the LEC may not be a general phenomenon but may be driven by the neural activity from a small subset of the animals. To test the generality of these results across animals, Figure 10 shows the rotation angles of each of the cells that met activity criteria in consecutive standard and mismatch sessions (i.e., cells that were classified as CCW, CW, or ambiguous) and the associated mean vectors, color-coded by subject. The two small insets to the right of each color-coded angle plot show the mean vector for the entire sample of cells (top) and the mean unit vector (bottom), presented to emphasize the angle of the mean vector. The mean vector length for MEC cells was significant for all mismatch angles $<180^{\circ}$ (denoted by an asterisk; Rayleigh's test, $p<$ 0.002 ). Furthermore, the direction of the mean vector in all mismatch sessions corresponded to a global cue rotation. LEC responses were more variable and only the mean vectors of the smallest and largest mismatch angles were significant (Rayleigh's test, $45^{\circ}$ and $\left.180^{\circ}, p<0.03\right)$. However, for all mismatch sessions, the angle of the mean vector corresponded to the direction of a local cue rotation. Note that there was no peak at the top of the circular plots for any mismatch angle in LEC or MEC. A peak at the top of the circular plots would have indicated that the firing of the cells was controlled by stable background cues in the recording environment; the lack of this peak indicated that the influence of such background cues was minimal. The distributions of rota- tion angles were similar for individual rats for each group of LEC and MEC recordings, although there was some variability across animals. To statistically analyze the data across animals, we determined for each rat a preference index for either the local or global cues. For each mismatch session of each rat, we calculated the angular distance between the angle of the mean vector of the sample of cells from that rat and (1) the angle of rotation of the local cues and (2) the angle of rotation of the global cues. This produced a set of four numbers indicating the deviation from local cue control for each mismatch angle and four numbers indicating the deviation from global cue control (Table 1). We then calculated the mean of each set of four numbers. For all three LEC rats, the mean deviation from the local cue control was less than the mean deviation from the global cue control. For all four MEC rats, the reverse was true. A $\chi^{2}$ test (corrected for low $n$; Bruning and Kintz, 1977) showed a trend toward significance of this comparison $\left(\chi^{2}=3.51, p=0.061\right)$. Thus, although the statistical test barely missed significance, it is unlikely that the difference between LEC and MEC was attributable to sampling errors of individual rats, because all rats within a group showed similar results.

\section{Discussion}

The cognitive map theory proposes that the hippocampus creates a spatial framework that organizes and interrelates the items and events of experience, such that they can be retrieved as a coherent memory (O'Keefe and Nadel, 1978). To understand the contribution of the hippocampus to memory in terms of information processing and computation, it is necessary to understand the information represented in its input structures. MEC cells show strong spatial signals in the forms of grid cells (Hafting et al., 2005), boundary (or border) cells (Savelli et al., 2008; Solstad et al., 2008), and head-direction cells (Sargolini et al., 2006), whereas LEC cells show much weaker spatial signals (Hargreaves et al., 2005; Yoganarasimha et al., 2011). In contrast, LEC cells show a stronger response to individual objects and object-location "memories" than MEC (Deshmukh and Knierim, 2011). The present study demonstrated a new dissociation between the MEC and the LEC when global and local reference frames were placed in conflict. MEC cells showed strong spatial tuning controlled by the global cues in the environment. LEC cells did not show strong spatial signals, but a highly statistically significant signal was detected that was controlled by the local cues on the track. Such reference frame conflicts are a standard strategy to reveal the influences of different sensory and self-motion cues on the spatial representations of the hippocampus (O'Keefe and Conway, 1978; Shapiro et al., 1997; Hargreaves et al., 2007) and have been studied as a model of cognitive coordination (Olypher et al., 2006). Because a key goal of systems neuroscience is to understand neural processing in terms of the functional connectivity within and between brain regions, the present results provide a striking demonstration of how different firing properties of brain regions in the hippocampus (CA1 vs CA3) may be explained in terms of different input patterns and different internal circuitry, as described below.

\section{MEC and distal cue control}

The MEC is often considered part of a spatial, "where" pathway that receives major input from the postrhinal cortex (Fig. 1) (Burwell, 2000; Knierim et al., 2006; Manns and Eichenbaum, 2006). Other inputs to the MEC from the presubiculum, parasubiculum, and retrosplenial cortex have grid cells, border cells, and head-direction cells, similar to MEC (Boccara et al., 2010). Thus, the spatial firing properties of MEC apparently derive more from 
A

$45^{\circ}$
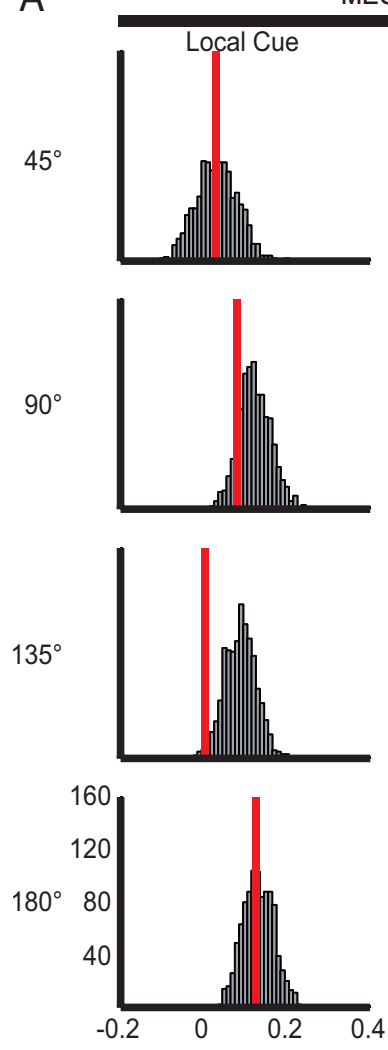

MEC
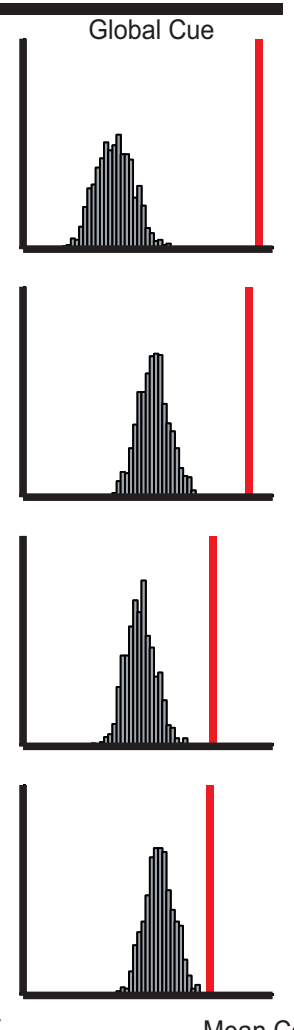

Mean Correlation
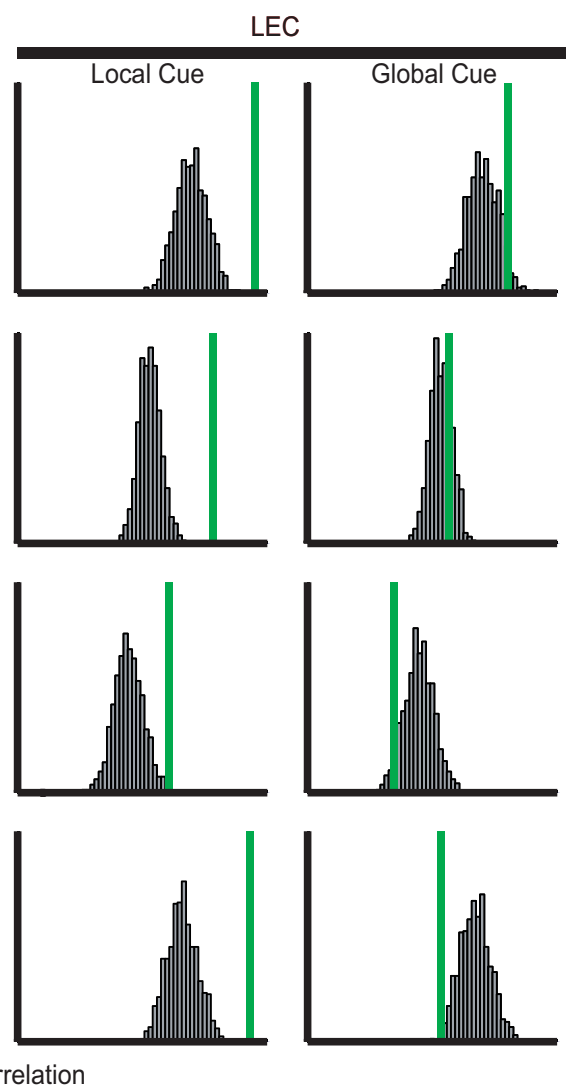

B

MEC

LEC

\begin{tabular}{|c|c|c|c|c|c|}
\hline & & 45 & 90 & 135 & 180 \\
\hline Cir & $\mathrm{L}$ & $\begin{array}{r}0.524 \\
<0.001\end{array}$ & $\begin{array}{r}0.874 \\
<0.001\end{array}$ & $\begin{array}{r}0.987 \\
<0.001\end{array}$ & $\begin{array}{r}0.560 \\
<0.001\end{array}$ \\
\hline Col & $\stackrel{L}{G}$ & $\begin{array}{r}0.249 \\
<0.001\end{array}$ & $\begin{array}{r}0.049 \\
<0.001\end{array}$ & $\begin{array}{r}0.451 \\
<0.001\end{array}$ & $\begin{array}{r}0.003 \\
<0.001\end{array}$ \\
\hline Row & $\stackrel{L}{G}$ & $\begin{array}{r}0.541 \\
<0.001\end{array}$ & $\begin{array}{l}>0.999 \\
<0.001\end{array}$ & $\begin{array}{l}>0.999 \\
<0.001\end{array}$ & $\begin{array}{l}0.780 \\
0.002\end{array}$ \\
\hline Bin & $\mathrm{L}$ & $\begin{array}{r}0.567 \\
<0.001\end{array}$ & $\begin{array}{l}>0.999 \\
<0.001\end{array}$ & $\begin{array}{l}>0.999 \\
<0.001\end{array}$ & $\begin{array}{r}0.829 \\
<0.001\end{array}$ \\
\hline
\end{tabular}

\begin{tabular}{|c|c|c|c|c|}
\hline & 15 & 90 & 135 & 180 \\
\hline$\stackrel{L}{G}$ & & $\begin{array}{r}<0.0 \\
0.2 \\
\end{array}$ & & $\begin{array}{r}<0.001 \\
0.991\end{array}$ \\
\hline $\mathrm{L}$ & & & & \\
\hline $\mathrm{L}$ & \begin{tabular}{|l}
$<0.001$ \\
$<0.001$
\end{tabular} & $\begin{array}{r}<0.001 \\
0.008\end{array}$ & $\begin{array}{r}0.001 \\
>0.999\end{array}$ & \\
\hline $\begin{array}{l}\mathrm{L} \\
\mathrm{G}\end{array}$ & $\begin{array}{l}<0.001 \\
<0.001\end{array}$ & $\begin{array}{r}<0.001 \\
0.007\end{array}$ & $\begin{array}{l}<0.001 \\
>0.999\end{array}$ & $\begin{array}{l}<0.001 \\
>0.999\end{array}$ \\
\hline
\end{tabular}

Figure 9. Data shuffling analyses. A, To determine whether the global and local cue control over MEC and LEC representations was greater than expected by chance, the mean correlations obtained from the shuffle analyses were compared with the actual data. The distributions (gray) show the results from the circle shift and the actual data (red lines, MEC; green lines, LEC) for all mismatch angles. Inspection of all local cue distributions for the LEC and global cue distributions for the MEC reveals that these correlations were all well above chance level ( $p<0.001)$. In contrast, the correlations for the nonpreferred cue set were not significant $(p>0.01) . B$, Chart shows the probabilities that correlations produced by the four types of shuffling procedures at locations predicted by local and global cue sets were greater than the real data. If the peak correlation for the real data corresponded to the local cues (L), the probability is displayed in green; if the peak correlation of the real data corresponded to the global cues $(G)$, the probability is displayed in red. For some of the smaller rotations, the nonpreferred cue set also had significant correlations, but the magnitude of the correlations was smaller than the preferred cue set.

interactions with these regions than with postrhinal cortex, which does not show similar signals (Burwell and Hafeman, 2003; Fyhn et al., 2004). Of particular interest for the current experiment is the head-direction cell system. Because the reference frame conflict was generated by rotations, it is likely that head-direction cells played a key role in dictating the response of the MEC (Knierim et al., 1995, 1998; Knierim and Hamilton, 2011). Head-direction cells are typically controlled by distal landmarks (Taube et al., 1990; Zugaro et al., 2001; Knight et al., 2011; but see Clark et al., 2012), including in the double-rotation manipulation (Yoganarasimha et al., 2006). Thus, given the strong relationship between head-direction cells and the MEC (Hargreaves et al., 2007) and the strong control of the global cues over the head-direction system, it is not surprising that the MEC cells were controlled by the global cues.
A number of the MEC cells showed an apparent "remapping" of the track in the double-rotation experiment (Fig. 4, cells 7, 9, 11,13 , and 14), resulting in the prevalence of cells that showed an ambiguous response to the double rotation and the increasingly weaker population correlations of the MEC response as the double rotation increased in magnitude from $45^{\circ}$ to $180^{\circ}$ (Figs. 7,8 ). Remapping is a hallmark property of hippocampal place cells (Bostock et al., 1991; Knierim, 2003), and it may underlie the role of the hippocampus in supporting context-dependent memories (Jeffery et al., 2004; Nadel, 2008). In contrast, MEC grid cells are not believed to demonstrate global remapping in the same way as place cells (Fyhn et al., 2007). It is possible that, under the present conditions, grid cells or other spatially selective MEC cells can show hippocampus-like global remapping. However, the most parsimonious explanation may be that the apparent remapping 


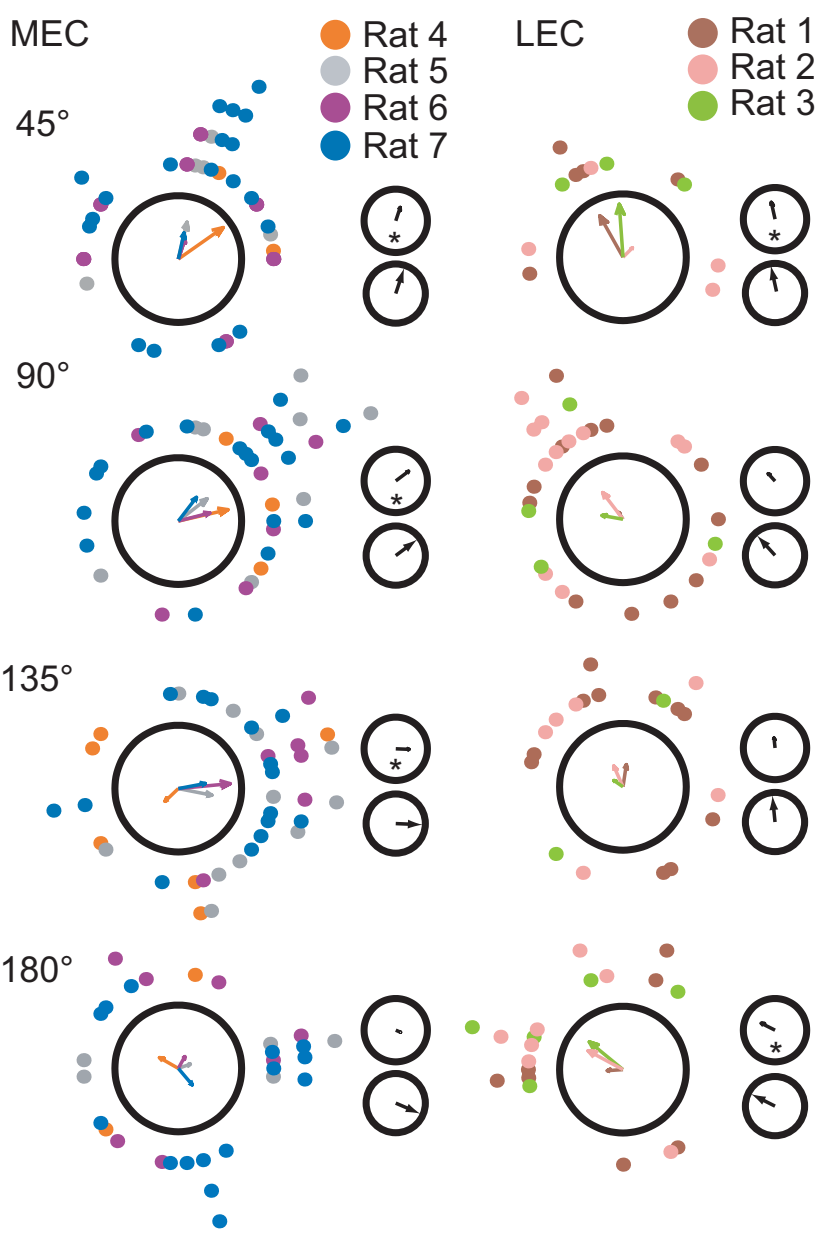

Figure 10. Individual cell responses and comparisons across subjects. Each dot indicates the amount that the spatial firing of a cell rotated between the standard and mismatch sessions, color coded to identify each rat $(n=7)$. Colored arrows represent the mean vectors for each rat. The distributions of rotation angles for LEC and MEC were similar for individual rats (Table 1). The small circles to the right of the main plots indicate the mean vector of the entire sample of cells collapsed across subjects (top) and the mean unit vector (bottom), added here to emphasize the orientation of the vector. The mean vector length for MEC cells was significant $\left.{ }^{*}\right)$ for all mismatch angles except for the $180^{\circ}$ mismatch, whereas the mean vector length for LEC was variable (Rayleigh's test; $\mathrm{LEC}, 45^{\circ}$ and $180^{\circ}, p<0.03 ; \mathrm{MEC}, 45^{\circ}, 90^{\circ}$, and $135^{\circ}, p<0.002$ ).

in the present experiment was an artifact of the limited sampling of the grid-cell firing pattern provided by the circular track (Yoganarasimha et al., 2011). If the underlying grid pattern rotated with the global cues but this rotation was accompanied by a horizontal shift of the grid pattern, some of the grid fields would rotate/shift off of the track and other grid fields would rotate/shift onto the track. The result would resemble hippocampal remapping, but the underlying dynamics of grid-cell firing would not have changed.

\section{LEC and external cues}

The LEC is often considered part of the nonspatial, "what" pathway that sends information about individual items to the hippocampus (Burwell, 2000; Knierim et al., 2006; Manns and Eichenbaum, 2006). In this conception, the LEC provides the content of an experience, whereas the MEC provides the spatial context. Consistent with this view, LEC cells respond to individual objects more strongly than MEC cells (Deshmukh and Knierim, 2011). However, in the presence of objects, a small fraction of LEC cells demonstrate clear spatial tuning that resembles hip-
Table 1. Individual rat comparison

\begin{tabular}{|c|c|c|c|c|c|}
\hline \multirow[b]{2}{*}{ Rat } & \multirow[b]{2}{*}{ Mismatch } & \multicolumn{2}{|c|}{ Angular deviation } & \multicolumn{2}{|c|}{ Mean angular deviation } \\
\hline & & From local & From global & From local & From global \\
\hline \multicolumn{6}{|l|}{ LEC } \\
\hline \multirow[t]{4}{*}{151} & 45 & 6.68 & 51.68 & 24.77 & 91.07 \\
\hline & 90 & 12.64 & 77.36 & & \\
\hline & 135 & 76.0 & 59.0 & & \\
\hline & 180 & 3.76 & 176.24 & & \\
\hline \multirow[t]{4}{*}{156} & 45 & 67.5 & 22.5 & 36.79 & 86.96 \\
\hline & 90 & 7.75 & 82.25 & & \\
\hline & 135 & 43.48 & 91.52 & & \\
\hline & 180 & 28.45 & 151.55 & & \\
\hline \multirow[t]{4}{*}{184} & 45 & 18.55 & 26.45 & 26.35 & 103.61 \\
\hline & 90 & 34.91 & 124.91 & & \\
\hline & 135 & 12.5 & 122.5 & & \\
\hline & 180 & 39.42 & 140.57 & & \\
\hline \multicolumn{6}{|l|}{ MEC } \\
\hline \multirow[t]{4}{*}{159} & 45 & 77.5 & 32.5 & 100.46 & 26.64 \\
\hline & 90 & 122.07 & 32.07 & & \\
\hline & 135 & 66.28 & 158.72 & & \\
\hline & 180 & 30.00 & 150.00 & & \\
\hline \multirow[t]{4}{*}{165} & 45 & 35.83 & 9.17 & 98.13 & 16.46 \\
\hline & 90 & 97.26 & 7.26 & & \\
\hline & 135 & 168.58 & 33.58 & & \\
\hline & 180 & 160.11 & 19.89 & & \\
\hline \multirow[t]{4}{*}{174} & 45 & 41.09 & 3.91 & 87.84 & 45.41 \\
\hline & 90 & 120.61 & 30.61 & & \\
\hline & 135 & 152.12 & 17.12 & & \\
\hline & 180 & 119.06 & 60.94 & & \\
\hline \multirow[t]{4}{*}{191} & 45 & 35.14 & 9.86 & 88.58 & 56.01 \\
\hline & 90 & 82.51 & 7.49 & & \\
\hline & 135 & 146.76 & 11.76 & & \\
\hline & 180 & 130.53 & 49.47 & & \\
\hline
\end{tabular}

pocampal place fields, even in locations unoccupied by objects. When familiar objects are moved, some LEC cells fire at the locations occupied previously by the objects (Deshmukh and Knierim, 2011; Tsao et al., 2013). Thus, there is some degree of spatial coding in the LEC in the presence of objects; this spatial signal appears to be absent from the perirhinal cortex (Deshmukh et al., 2012). The distinction between the MEC and LEC may be best described as the MEC supporting path integration mechanisms to create a self-motion-based, internal spatial framework (O'Keefe and Burgess, 2005; Fuhs and Touretzky, 2006; McNaughton et al., 2006; Hasselmo, 2012), whereas the LEC processes information about the external sensory environment (Deshmukh and Knierim, 2011; Deshmukh et al., 2012). This information can be used for both spatial and nonspatial computations. This notion is similar to a proposal that the distinction between LEC and MEC is best described as one of cue versus action or non-self versus self (Lisman, 2007). In the present experiment, we hypothesize that the weak spatial signal of LEC cells is tied to the sensory cues provided by the different textures, odors, and visual patterns of the track. Whether this signal is a true spatial signal like that of place cells or whether it is a signal produced by some variable correlated with spatial location (e.g., local views) is unclear.

\section{EC inputs to CA3 and CA1}

Previous studies of the double-rotation protocol demonstrated a dissociation between the CA3 and CA1 fields of the hippocampus (Lee et al., 2004) (Fig. 11A). Place fields recorded from the proximal half of CA1 (i.e., the part close to CA3) showed a split response to the double rotation, because some place fields rotated CW to follow the global cues, others rotated CCW to follow the 

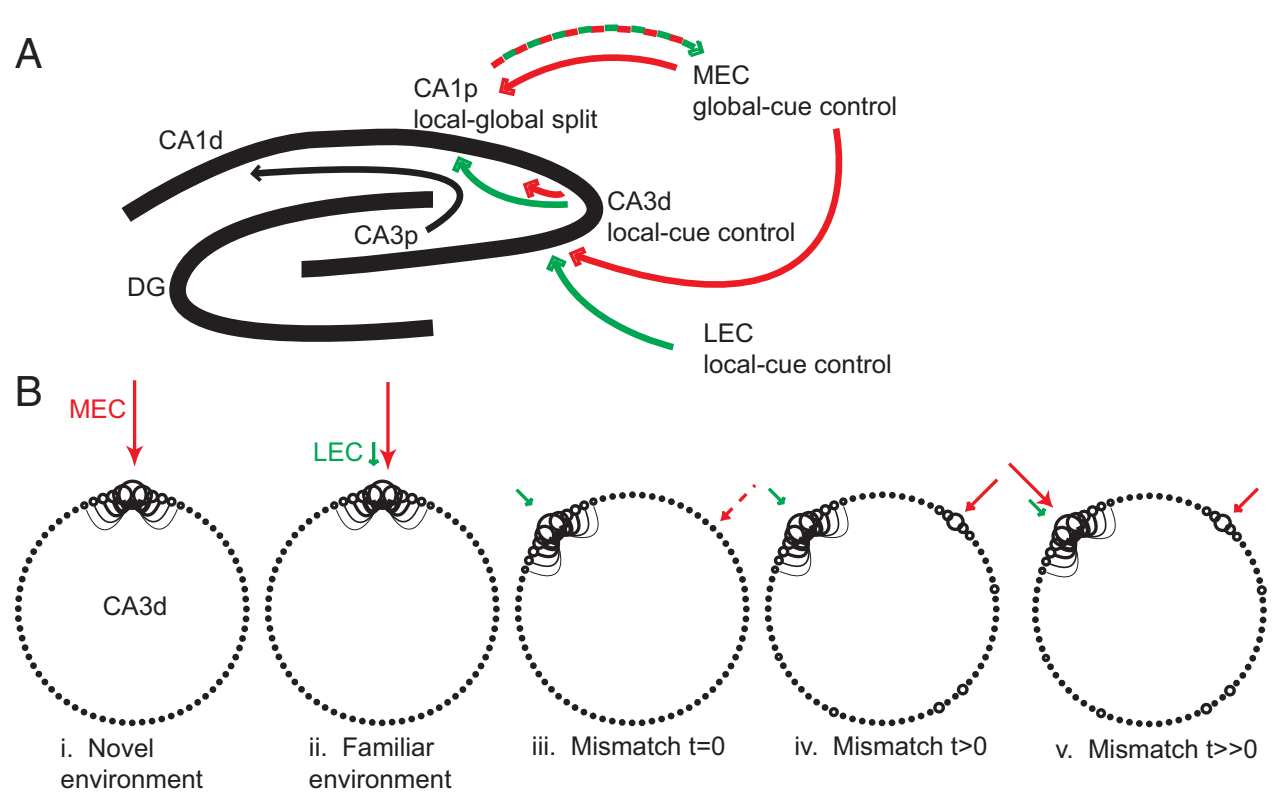

Figure 11. Functional anatomy of local- global cue influences on the CA1 and CA3 networks. $A$, Previous studies have shown that the proximal CA1 region (CA1p, the region of CA1 closer to CA3) shows a split representation in the double rotation experiment, whereas the distal CA3 region (CA3d, the region of CA3 closer to CA1 and which projects to CA1p) shows a more coherent representation than CA1p; the CA3d representation is controlled by the local cues. CA1p also receives direct input from MEC. Thus, the split representation of CA1p may be the result of conflicting inputs it receives from CA3d and MEC. This split representation is returned to MEC by a feedback pathway to the deep layers of MEC. The joint local-global control in the CA1 output under the extreme cue conflicts of the present experiment may be an aberrant reflection of the normal processing of CA1 because it compares the incoming input from MEC about the current state of the animal's experience with the stored memories in CA3 of the animal's previous experience. $B$, Conceptual model of how putative attractor dynamics of CA3 might cause the local-cue dominance over CA3 place fields. For simplicity, CA3 is represented as a ring attractor to illustrate the firing of the cells on the circular track rather than its standard conception as a 2D sheet or point attractor. Each circle represents a CA3 cell that fires when the rat is on the corresponding location on the track; the diameter of the circle indicates the current firing rate. Excitatory connections between cells with nearby place fields are shown, with the strength of connection decreasing with place field distance. With appropriate weights and global inhibition (data not shown), an attractor forms. The location of the "bump" of activity can be set even by a weak external input (Zhang, 1996). Active external inputs from MEC and LEC are shown as colored lines. The length of the line corresponds to the relative strength of the input. $i$, In a novel environment, it is assumed that the spatial firing of the network is driven primarily by MEC inputs. $i i$, After the environment is familiar, it is assumed that local cue information from LEC has acquired, through a Hebbian association, a degree of control over the CA3 activity. The arrow is small, indicating that the spatial signal of LEC is weak. iii, In the first moments after the rat is placed on the track in the mismatch session (here depicted as a $90^{\circ}$ mismatch), we hypothesize that MEC inputs are compromised as a result of potential attentional mechanisms in which the rat first attends to the local cues as it is placed on the track. Thus, the bump of activity is initially controlled by the weak, local-cue-dominated signals demonstrated by LEC. iv, When the rat switches attention to the global landmarks, the MEC grid is aligned and excites the CA3 network at the location predicted by global cues. However, if the attractor dynamics are strong, the bump of activity already present at the local-cue-predicted location might hinder the ability of this external drive to control the bump. Nonetheless, the external drive could still excite these cells to some degree, causing perturbations in the network that allow cells at other location to become active (partial remapping). $\boldsymbol{v}$, After a few laps, we predict that CA3 and MEC cells learn a new mapping, such that MEC can take over its normal role as a primary drive on the spatial firing of the CA3 cells. Perhaps the secondary bump would disappear over time if the mismatch environment remains stable, as that bump loses the competition with the stronger bump that is consistent with inputs from CA3, LEC, and MEC.

local cues, others split into two subfields, and others remapped. In contrast, place fields recorded from distal CA3 (the region that projects to proximal CA1) showed a more coherent response that was controlled more by the local cues than the global cues. One question that remains is why the CA1 cells displayed split responses, when their inputs from CA3 showed a more coherent response. Proximal CA1 receives input from distal CA3 and from the MEC but not from LEC (Witter and Amaral, 2004). Thus, under these conditions, proximal CA1 receives a strong globalcue-dominated signal from $\mathrm{MEC}$ and a strong local-cuedominated signal from CA3. CA1, lacking a recurrent collateral system or feedback inputs, functions more as a pure feedforward network. Because its two major inputs provided strong, but conflicting, signals, proximal CA1 responded with an output that reflected the conflict in its inputs. It will be interesting in future studies to determine whether the CA1 output related to the local versus global cues can be related to the differential gammafrequency coherence of CA1 with MEC versus CA3 (Colgin et al., 2009).

Why does CA3 follow the local cues?

CA3 presumably also receives conflicting input from the MEC and LEC (Witter and Amaral, 2004). However, unlike CA1, the
CA3 response is dominated by the local reference frame (Lee et al., 2004), an effect replicated in a separate group of animals (J.P.N. and J.J.K., unpublished observations). This result is counterintuitive, because most models suggest that the grid-cell inputs from the MEC are the spatial signal that drives hippocampal place cells (McNaughton et al., 2006; Solstad et al., 2006; de Almeida et al., 2009; Savelli and Knierim, 2010; Monaco and Abbott, 2011). A number of reports have challenged this simple model, showing that at least some place fields are independent of grid-cell inputs (Miller and Best, 1980; Van Cauter et al., 2008; Koenig et al., 2011; Schlesiger et al., 2012; Song et al., 2012). Nonetheless, can one explain the local-cue dominance of CA3 when the information about the local cues is apparently so weak? Attractor network theories inspired by the recurrent collateral circuitry of CA3 may provide an answer (Fig. 11B). In a continuous attractor network, a weak external input can bias the network to form a "bump of activity" at a location determined by that weak input (Zhang, 1996). Based on recent work exploring the role of top-down, attentional signals in the dynamics of place fields (Kentros et al., 2004; Johnson et al., 2009; Fenton et al., 2010), we hypothesize that the local cues on the track may be the first set of cues to which the animal attends when its feet are placed on the track. The weak signals from the LEC may be sufficient to cause the CA3 bump of 
activity to form at the location corresponding to the local cues. When the rat subsequently attends to the distal landmarks, the strong attractor dynamics of CA3 may prevent the bump from moving to the representation of the location corresponding to the global cues. As the rat traverses the track, we hypothesize that Hebbian plasticity causes a new mapping of active grid cells to CA3 place cells, allowing the grid cells to "relearn" to drive the CA3 place fields at the locations that now correspond to the original local cues (Savelli and Knierim, 2010). This model reinforces the notions that the hippocampus (in particular the CA3 field) must be understood not only in terms of its sensory inputs but also in terms of such cognitive factors as attentional control, learning, and nonlinear network dynamics.

\section{References}

Alonso A, García-Austt E (1987a) Neuronal sources of theta rhythm in the entorhinal cortex of the rat. I. Laminar distribution of theta field potentials. Exp Brain Res 67:493-501. CrossRef Medline

Alonso A, García-Austt E (1987b) Neuronal sources of theta rhythm in the entorhinal cortex of the rat. II. Phase relations between unit discharges and theta field potentials. Exp Brain Res 67:502-509. CrossRef Medline

Boccara CN, Sargolini F, Thoresen VH, Solstad T, Witter MP, Moser EI, Moser MB (2010) Grid cells in pre- and parasubiculum. Nat Neurosci 13:987-994. CrossRef Medline

Bostock E, Muller RU, Kubie JL (1991) Experience-dependent modifications of hippocampal place cell firing. Hippocampus 1:193-205. CrossRef Medline

Brown JE, Skaggs WE (2002) Concordant and discordant coding of spatial location in populations of hippocampal CA1 pyramidal cells. J Neurophysiol 88:1605-1613. Medline

Bruning JL, Kintz BL (1977) Computational handbook of statistics, Ed 2. Glenview, IL: Scott, Foresman and Company.

Burwell RD (2000) The parahippocampal region: corticocortical connectivity. Ann N Y Acad Sci 911:25-42. Medline

Burwell RD, Hafeman DM (2003) Positional firing properties of postrhinal cortex neurons. Neuroscience 119:577-588. CrossRef Medline

Clark BJ, Harris MJ, Taube JS (2012) Control of anterodorsal thalamic head direction cells by environmental boundaries: comparison with conflicting distal landmarks. Hippocampus 22:172-187. CrossRef Medline

Cohen NJ, Eichenbaum H (1993) Memory, amnesia, and the hippocampal system. Cambridge, MA: Massachusetts Institute of Technology.

Colgin LL, Denninger T, Fyhn M, Hafting T, Bonnevie T, Jensen O, Moser MB, Moser EI (2009) Frequency of gamma oscillations routes flow of information in the hippocampus. Nature 462:353-357. CrossRef Medline

de Almeida L, Idiart M, Lisman JE (2009) The input-output transformation of the hippocampal granule cells: from grid cells to place fields. J Neurosci 29:7504-7512. CrossRef Medline

Deshmukh SS, Knierim JJ (2011) Representation of non-spatial and spatial information in the lateral entorhinal cortex. Front Behav Neurosci 5:69. CrossRef Medline

Deshmukh SS, Johnson JL, Knierim JJ (2012) Perirhinal cortex represents nonspatial, but not spatial, information in rats foraging in the presence of objects: comparison with lateral entorhinal cortex. Hippocampus 22:2045-2058. CrossRef Medline

Fenton AA, Lytton WW, Barry JM, Lenck-Santini PP, Zinyuk LE, Kubík S, Bures J, Poucet B, Muller RU, Olypher AV (2010) Attention-like modulation of hippocampus place cell discharge. J Neurosci 30:4613-4625. CrossRef Medline

Fuhs MC, Touretzky DS (2006) A spin glass model of path integration in rat medial entorhinal cortex. J Neurosci 26:4266-4276. CrossRef Medline

Furtak SC, Ahmed OJ, Burwell RD (2012) Single neuron activity and theta modulation in postrhinal cortex during visual object discrimination. Neuron 76:976-988. CrossRef Medline

Fyhn M, Molden S, Witter MP, Moser EI, Moser MB (2004) Spatial representation in the entorhinal cortex. Science 305:1258-1264. CrossRef Medline

Fyhn M, Hafting T, Treves A, Moser MB, Moser EI (2007) Hippocampal remapping and grid realignment in entorhinal cortex. Nature 446: 190-194. CrossRef Medline

Hafting T, Fyhn M, Molden S, Moser MB, Moser EI (2005) Microstructure of a spatial map in the entorhinal cortex. Nature 436:801-806. CrossRef Medline

Hamilton DA, Akers KG, Johnson TE, Rice JP, Candelaria FT, Sutherland RJ, Weisend MP, Redhead ES (2008) The relative influence of place and direction in the Morris water task. J Exp Psychol Anim Behav Process 34:31-53. CrossRef Medline

Hargreaves EL, Rao G, Lee I, Knierim JJ (2005) Major dissociation between medial and lateral entorhinal input to dorsal hippocampus. Science 308 : 1792-1794. CrossRef Medline

Hargreaves EL, Yoganarasimha D, Knierim JJ (2007) Cohesiveness of spatial and directional representations recorded from neural ensembles in the anterior thalamus, parasubiculum, medial entorhinal cortex, and hippocampus. Hippocampus 17:826-841. CrossRef Medline

Hasselmo MA (2012) How we remember: brain mechanisms of episodic memory. Cambridge, MA: Massachusetts Institute of Technology.

Jeffery KJ, Anderson MI, Hayman R, Chakraborty S (2004) A proposed architecture for the neural representation of spatial context. Neurosci Biobehav Rev 28:201-218. CrossRef Medline

Johnson A, Fenton AA, Kentros C, Redish AD (2009) Looking for cognition in the structure within the noise. Trends Cogn Sci 13:55-64. CrossRef Medline

Kentros CG, Agnihotri NT, Streater S, Hawkins RD, Kandel ER (2004) Increased attention to spatial context increases both place field stability and spatial memory. Neuron 42:283-295. CrossRef Medline

Knierim JJ (2002) Dynamic interactions between local surface cues, distal landmarks, and intrinsic circuitry in hippocampal place cells. J Neurosci 22:6254-6264. Medline

Knierim JJ (2003) Hippocampal remapping: Implications for spatial learning and memory. In: The neurobiology of spatial behaviour (Jeffery $\mathrm{K}$, ed), pp 226-223. Oxford: Oxford UP.

Knierim JJ, Hamilton DA (2011) Framing spatial cognition: neural representations of proximal and distal frames of reference and their roles in navigation. Physiol Rev 91:1245-1279. CrossRef Medline

Knierim JJ, Rao G (2003) Distal landmarks and hippocampal place cells: effects of relative translation versus rotation. Hippocampus 13:604-617. CrossRef Medline

Knierim JJ, Kudrimoti HS, McNaughton BL (1995) Place cells, head direction cells, and the learning of landmark stability. J Neurosci 15: 1648-1659. Medline

Knierim JJ, Kudrimoti HS, McNaughton BL (1998) Interactions between idiothetic cues and external landmarks in the control of place cells and head direction cells. J Neurophysiol 80:425-446. Medline

Knierim JJ, Lee I, Hargreaves EL (2006) Hippocampal place cells: parallel input streams, subregional processing, and implications for episodic memory. Hippocampus 16:755-764. CrossRef Medline

Knight R, Hayman R, Lin Ginzberg L, Jeffery K (2011) Geometric cues influence head direction cells only weakly in nondisoriented rats. J Neurosci 31:15681-15692. CrossRef Medline

Koenig J, Linder AN, Leutgeb JK, Leutgeb S (2011) The spatial periodicity of grid cells is not sustained during reduced theta oscillations. Science 332: 592-595. CrossRef Medline

Lee I, Yoganarasimha D, Rao G, Knierim JJ (2004) Comparison of population coherence of place cells in hippocampal subfields CA1 and CA3. Nature 430:456-459. CrossRef Medline

Lisman JE (2007) Role of the dual entorhinal inputs to hippocampus: a hypothesis based on cue/action (non-self/self) couplets. Prog Brain Res 163:615-625. CrossRef Medline

Louie K, Wilson MA (2001) Temporally structured replay of awake hippocampal ensemble activity during rapid eye movement sleep. Neuron 29:145-156. CrossRef Medline

Manns JR, Eichenbaum H (2006) Evolution of declarative memory. Hippocampus 16:795-808. CrossRef Medline

McNaughton BL, Battaglia FP, Jensen O, Moser EI, Moser MB (2006) Path integration and the neural basis of the "cognitive map." Nat Rev Neurosci 7:663-678. CrossRef

Miller VM, Best PJ (1980) Spatial correlates of hippocampal unit activity are altered by lesions of the fornix and entorhinal cortex. Brain Res 194:311323. CrossRef Medline

Monaco JD, Abbott LF (2011) Modular realignment of entorhinal grid cell activity as a basis for hippocampal remapping. J Neurosci 31:9414-9425. CrossRef Medline

Nadel L (2008) The hippocampus and context revisited. In: Hippocampal 
place fields: relevance to learning and memory (Mizumori SJ, ed), pp 3-15. Oxford: Oxford UP.

O'Keefe J (1976) Place units in the hippocampus of the freely moving rat. Exp Neurol 51:78-109. CrossRef Medline

O'Keefe J, Burgess N (2005) Dual phase and rate coding in hippocampal place cells: theoretical significance and relationship to entorhinal grid cells. Hippocampus 15:853-866. CrossRef Medline

O'Keefe J, Conway DH (1978) Hippocampal place units in the freely moving rat: why they fire where they fire. Exp Brain Res 31:573-590. Medline

O'Keefe J, Nadel L (1978) The hippocampus as a cognitive map. Oxford: Clarendon.

Olypher AV, Klement D, Fenton AA (2006) Cognitive disorganization in hippocampus: a physiological model of the disorganization in psychosis. J Neurosci 26:158-168. CrossRef Medline

Renaudineau S, Poucet B, Save E (2007) Flexible use of proximal objects and distal cues by hippocampal place cells. Hippocampus 17:381-395. CrossRef Medline

Sargolini F, Fyhn M, Hafting T, McNaughton BL, Witter MP, Moser MB, Moser EI (2006) Conjunctive representation of position, direction, and velocity in entorhinal cortex. Science 312:758-762. CrossRef Medline

Savelli F, Knierim JJ (2010) Hebbian analysis of the transformation of medial entorhinal grid-cell inputs to hippocampal place fields. J Neurophysiol 103:3167-3183. CrossRef Medline

Savelli F, Yoganarasimha D, Knierim JJ (2008) Influence of boundary removal on the spatial representations of the medial entorhinal cortex. Hippocampus 18:1270-1282. CrossRef Medline

Schlesiger MI, Hales JB, Leutgeb JK, Leutgeb S (2012) Hippocampal place cell stability after lesions of the grid cell area in the medial entorhinal cortex. Soc Neurosci Abstr 38:203.02.

Scoville WB, Milner B (1957) Loss of recent memory after bilateral hippocampal lesions. J Neurol Neurosurg Psychiatry 20:11-21. CrossRef Medline

Shapiro ML, Tanila H, Eichenbaum H (1997) Cues that hippocampal place cells encode: dynamic and hierarchical representation of local and distal stimuli. Hippocampus 7:624-642. CrossRef Medline

Siegel JJ, Neunuebel JP, Knierim JJ (2008) Dominance of the proximal coordinate frame in determining the locations of hippocampal place cell activity during navigation. J Neurophysiol 99:60-76. Medline

Solstad T, Moser EI, Einevoll GT (2006) From grid cells to place cells: a mathematical model. Hippocampus 16:1026-1031. CrossRef Medline

Solstad T, Boccara CN, Kropff E, Moser MB, Moser EI (2008) Representation of geometric borders in the entorhinal cortex. Science 322:1865-1868. CrossRef Medline

Song E, Fox SE, Rivard B, Muller RU (2012) Neuronal representations of two visual stimuli modifications on the network level of the spatial cognition in rat brain. Soc Neurosci Abstr 38:293.05.

Squire LR (1987) Memory and brain. Oxford: Oxford UP.

Taube JS, Muller RU, Ranck JB Jr (1990) Head-direction cells recorded from the postsubiculum in freely moving rats. II. Effects of environmental manipulations. J Neurosci 10:436-447. Medline

Tsao A, Moser MB, Moser EI (2013) Traces of experience in the lateral entorhinal cortex. Curr Biol 23:399-405. CrossRef Medline

Van Cauter T, Poucet B, Save E (2008) Unstable CA1 place cell representation in rats with entorhinal cortex lesions. Eur J Neurosci 27:1933-1946. CrossRef Medline

Van Cauter T, Camon J, Alvernhe A, Elduayen C, Sargolini F, Save E (2013) Distinct roles of medial and lateral entorhinal cortex in spatial cognition. Cereb Cortex 23:451-459. CrossRef Medline

Wilson DI, Langston RF, Schlesiger MI, Wagner M, Watanabe S, Ainge JA (2013) Lateral entorhinal cortex is critical for novel object-context recognition. Hippocampus 23:352-366. CrossRef Medline

Witter MP, Amaral DG (2004) Hippocampal formation. In: The rat nervous system, Ed 3 (Paxinos G, ed), pp 635-704. Amsterdam: Elsevier.

Yoganarasimha D, Yu X, Knierim JJ (2006) Head direction cell representations maintain internal coherence during conflicting proximal and distal cue rotations: comparison with hippocampal place cells. J Neurosci 26 : 622-631. CrossRef Medline

Yoganarasimha D, Rao G, Knierim JJ (2011) Lateral entorhinal neurons are not spatially selective in cue-rich environments. Hippocampus 21:1363-1374. CrossRef Medline

Zhang K (1996) Representation of spatial orientation by the intrinsic dynamics of the head-direction cell ensemble: a theory. J Neurosci 16:21122126. Medline

Zinyuk L, Kubik S, Kaminsky Y, Fenton AA, Bures J (2000) Understanding hippocampal activity by using purposeful behavior: place navigation induces place cell discharge in both task-relevant and task-irrelevant spatial reference frames. Proc Natl Acad Sci U S A 97:3771-3776. CrossRef Medline

Zugaro MB, Berthoz A, Wiener SI (2001) Background, but not foreground, spatial cues are taken as references for head direction responses by rat anterodorsal thalamus neurons. J Neurosci 21:RC154(1-5). Medline 